\title{
Special Issue on Operation Tomodachi-Fire Research
}

\author{
Samuel L. Manzello*, Fire Research Division, National Institute of Standards \\ and Technology (NIST), Gaithersburg, MD, USA \\ Sayaka Suzuki, Large Fire Laboratory, National Research Institute of Fire and \\ Disaster (NRIFD), Chofu, Tokyo, Japan
}

Tomodachi means friendship in Japanese. The articles in this special issue are the result of a collaboration between NIST's Engineering Laboratory (EL-NIST), and the Japan Association for Fire Science and Engineering (JAFSE). Dr. Sayaka Suzuki of the National Research Institute of Fire and Disaster (NRIFD) served as the liaison between JAFSE and EL-NIST.

This collaboration was a formal continuation of the kickoff meeting held at ELNIST in June, 2011. Due to the success of the kickoff meeting, EL-NIST signed a Statement of Intent with JAFSE to hold two workshops, the first held in Tokyo in 2012 (see Manzello et al. [1] for a summary of that workshop), and the second on March 16-18, 2015. The objective of the relationship was to: (1) develop scientific knowledge and translate it to building codes and standards that will be of use to both countries to reduce the devastation caused by unwanted fires, (2) provide a forum for next generation researchers to present their work in order to develop research collaborations, (3) and allow participants a chance to visit.

To this end, oral presentations were focused on two topics: large outdoor fires (LOF) and fire-structure interaction (FSI). Justifications on why these two topics were chosen are provided elsewhere [1]. In addition, poster sessions were held in the areas of LOF and FSI, as well as two general fire safety science poster sessions. All of the presentations were documented in a recent NIST Special Publication 1189 [2]. These presentations provide a flavor of some of state of the art research in LOF and FSI ongoing in both countries. 21 papers were submitted to the special issue, and 12 were accepted for publication.

\section{Fire-Structure Inferaction (FSI)}

In the manuscript by Bundy et al. [3], a detailed description of the newly developed NFRL, a unique experimental facility to conduct fire-structure interaction experiments, may be found. The NRFL facility affords the ability to expose fullscale, loaded structural systems to realistic fires up to $20 \mathrm{MW}$.

\footnotetext{
* Correspondence should be addressed to: Samuel L. Manzello, E-mail: samuelm@nist.gov
} 
Naturally, the development of numerical models is of great important to be able to access structure member performance under a broad parameter space. A finite element based numerical model is presented by Kodur and Agarwal [4] to predict the residual response of reinforced concrete (RC) beams to fire exposures. Selden and Varma [5] described a two-dimensional modeling technique developed for predicting the moment capacity of composite beams at elevated temperatures. As presented by these authors, the desire is that their model may be easily implemented by designers [5].

On another note, the use of wood in high rise construction is an active research area presently in the fire safety science field. Suzuki et al. [6] conducted intricate experiments on the performance of various wood building elements exposed to standard fire exposures. These results are useful to the fire safety science community as most large-scale furnace test data is proprietary and not available in the open literature.

\section{Large Outdoor Fires (LOF)}

McAllister and Finney [7] presented interesting experiments to study the influence of the burning rate for wood cribs, with implications for greater understanding of large outdoor fire spread. In their work, a detailed description on the influence of wind on the flame structure is provided. Suzuki et al. [8] describe experiments on ignition behaviors of fencing assemblies exposed to firebrand attack. Firebrands are a known important mechanism of fire spread in large outdoor fires, yet little quantitative information is available on the ignition vulnerabilities of structures exposed to firebrand showers.

Dobashi et al. [9] investigated flame height and radiant heat of fire whirls, another concern in large outdoor fires, using laboratory scale experiments. Fire whirls have been observed in large outdoor fires, as far back as the 1923 Great Kanto Earthquake in Japan, but the mechanism of their generation remains elusive after considerable research on this topic.

Nishio et al. [10] described the development of a new Japanese testing method to cope with combustible building facades for realistic-scales. Nakamura et al. [11] describe fundamental burning behaviors of thermoplastic materials using laboratory scale experiments. Such fundamental burning behavior has wide range applicability to various aspects of fire safety science.

Large urban fire spread that occurs after earthquakes is a significant concern in earthquake prone countries. Meacham [12] discussed a large collaborative effort to understand the fire performance of buildings subjected to simulated earthquake exposures. Tsunami-induced fire spread research became an active topic after the March, 2011 Great East Japan Earthquake. To this end, Nishino and Imazu [13] numerically investigated the drift and accumulation of Tsunami-driven combustible objects, in an effort to begin to develop a Tsunami-induced fire spread simulation.

While most the manuscripts within the LOF area were concerned with the spread of fire, Torikai et al. [14] considered the aspect of developing a new suppression strategy for large outdoor fires. In particular, the use of liquid nitrogen 
filled capsules is proposed. While this methodology is still in the development stages, rather interesting results are presented in the manuscript. It is desired that the reader finds these contributed papers useful and this issue will bring greater attention to these challenging research areas.

\section{References}

1. Manzello SL et al (2013) Summary of workshop for fire structure interaction and urban and wildland-urban interface (WUI) fires - operation Tomodachi-fire research. Fire Saf J 59:122-131. doi:10.1016/j.firesaf.2013.03.021

2. Manzello SL, Suzuki S (2015) Summary of workshop for fire-structure interaction and large outdoor fires, operation tomodachi-fire research, NIST SP 1189. doi:10.6028/ NIST.SP.1189

3. Bundy MF, Hamins A, Gross J, Grosshandler WL, Choe L (2016) Structural fire experimental capabilities in the NIST national fire research laboratory. Fire Technol. doi:10.1007/s10694-015-0544-4

4. Kodur V, Agarwal A (2016) Critical factors governing the residual response of reinforced concrete beams exposed to fire. Fire Technol. doi:10.1007/s10694-015-0527-5

5. Selden K, Varma A (2016) Flexural capacity of composite beams subjected to fire: fiber based models and benchmarking. Fire Technol. doi:10.1007/s10694-016-0565-7

6. Suzuki J, Mizukami T, Naruse T, Araki Y (2016) Fire resistance of timber panel structures under standard fire exposures. Fire Technol. doi:10.1007/s10694-016-0578-2

7. McAllister S, Finney M (2016) The effect of wind on the burning rate of wood cribs. Fire Technol. doi:10.1007/s10694-015-0536-4

8. Suzuki S, Johnsson E, Maranghides A, Manzello SL (2016) Ignition of wood fencing assemblies exposed to continuous firebrand showers. Fire Technol. doi:10.1007/s10694$015-0520-z$

9. Dobashi R, Okura T, Nagaoka R, Hayashi Y, Mogi T (2016) Experimental study on flame height and radiant heat of fire whirls. Fire Technol. doi:10.1007/s10694-015-0549-Z

10. Nishio Y, Yoshioka H, Noguchi T, Kanematsu M, Ando T, Hase Y, Hayakawa T (2016) Fire spread caused by combustible facades in Japan. Fire Technol. doi:10.1007/ s10694-015-0535-5

11. Nakamura Y, Kizawa K, Mizuguchi S, Hosgai A, Wakatsuki K (2016) Experimental study on near-limiting burning behavior of thermoplastic materials with various thicknesses under candle-like burning configuration. Fire Technol. doi:10.1007/S10694-0160567-5

12. Meacham BJ (2016) Post-earthquake fire performance of buildings: summary of a large-scale experiment and conceptual framework for integrated performance-based seismic and fire design. Fire Technol. doi:10.1007/s10694-015-0523-9

13. Nishino T, Imazu Y (2016) Modeling of the drift and accumulation of tsunami-driven combustible objects: towards tsunami-induced fire spread simulation. Fire Technol. doi:10.1007/s10694-015-0519-5

14. Torikai H, Ishidoya M, Ito A (2016) Examination of extinguishment method with liquid nitrogen packed in a spherical ice capsule. Fire Technol. doi:10.1007/s10694-0150534-6 